\title{
Preliminary evaluation of fruit traits and phytochemicals in a highbush blueberry seedling population
}

\author{
Jessica Scalzo ${ }^{\mathrm{a}, *}$, Jill Stanley $^{\mathrm{b}}$, Peter Alspach ${ }^{\mathrm{c}}$ and Bruno Mezzetti ${ }^{\mathrm{d}}$ \\ ${ }^{a}$ The New Zealand Institute for Plant \& Food Research Limited (Plant \& Food Research, PFR), Havelock North, \\ New Zealand \\ ${ }^{\mathrm{b}}$ Plant \& Food Research, Clyde Research Centre, Alexandra, New Zealand \\ ${ }^{\mathrm{c}}$ Plant \& Food Research, Motueka Research Centre, Motueka, New Zealand \\ ${ }^{\mathrm{d}}$ Dipartimento di Scienze Agrarie, Alimentari ed Ambientali, Università Politecnica delle Marche, Ancona, Italy
}

Received 19 February 2013; accepted 8 May 2013

\begin{abstract}
.
BACKGROUND: The fruit quality traits and the phytochemical content of blueberries are of increasing importance to researchers in the field of food and health and important breeding objectives.

OBJECTIVE: The aim of this study was to gain preliminary information on parent's performances and variation of the fruit traits and phytochemicals from a small breeding population.

METHODS: The breeding population was from a $3 \times 4$ factorial mating design, 120 seedlings in total. The fruit traits evaluated were weight, colour, pedicel scar size and firmness and the phytochemical composition included the total anthocyanin and phenolic contents and total antioxidant activity.

RESULTS: Variation was found for all the traits studied in all families, with low genetic correlations between fruit traits, high correlations between phytochemicals and negative correlations between fruit weight and phytochemicals.

CONCLUSIONS: Breeding population size was small and the lack of replication has influenced the statistical approach. From our observations we found 'Hortblue Petite' potentially an excellent parent for phytochemical traits.

Keywords: Breeding, highbush blueberry, Vaccinium corymbosum L., fruit traits, antioxidants, anthocyanins, phenols, factorial mating design
\end{abstract}

\section{Introduction}

Improvement in fruit quality is a major breeding objective for the Plant \& Food Research (PFR) highbush blueberry (Vaccinium corymbosum L.) breeding programme, along with other horticultural traits such as yield and disease resistance. Important components of blueberry fruit quality that have been targeted for breeding include berry weight and colour, pedicel scar size and fruit firmness. Although these fruit traits are commercially important, they are not the sole focus of our breeding programme. The health attributes of berryfruit, particularly those of blueberry, are also becoming increasingly of interest to consumers.

* Corresponding author: Dr. Jessica Scalzo, The New Zealand Institute for Plant \& Food Research Limited (Plant \& Food Research), Private Bag 1401, Havelock North 4157, New Zealand. Tel.: +64 06 9758908; Fax: +64 069758881 ; E-mail: Jessica.scalzo@plantandfood.co.nz. 
Blueberries are regarded as "superfruits", which are thought to provide many health benefits beyond nutrition $[1,2]$. Polyphenolic compounds are thought to be the major health-promoting compounds in plant foods, because they are potent in vitro antioxidants and more recently, many other potential health benefits have been found that are unrelated to antioxidant capacity. These benefits include reduced incidence of cardiovascular disease, diabetes and cancer [2-4], as well as mechanistic properties that contribute to the epidemiological benefits, such as management of inflammation [2,3], stimulation of antioxidant and xenobiotic [4] metabolising enzymes (thus reducing DNA and protein damage by free radicals and toxicity of xenobiotics) and augmentation of the effects of exercise [5, 6]. Anthocyanins are the major polyphenols in blueberries and this group of phytochemicals is thought to be responsible for many of the health benefits of berry consumption [7-16]. This considerable interest in anthocyanins and health has resulted in a drive to breed, or find naturally, new blueberry cultivars with ever higher anthocyanin content, in addition to the usual requirements of commercial cultivars such as yield, taste, disease resistance.

Anthocyanins, which provide blueberry with their characteristic colours, vary in their quantity and composition among genotypes $[17,18]$.

In this study, we consider the total anthocyanin content of blueberry fruit as part of the phytochemical composition of the berries alongside with the total phenolic content and the total antioxidant activity of the fruit.

The aim of this study was to gain preliminary information on variation of the fruit traits and phytochemicals previously described in a small breeding population (120 seedlings) of highbush blueberry derived from a factorial mating design of twelve parents $(3 \times 4)$. Parent's performances were observed to achieve an understanding of their ability to pass on their traits to their progenies.

\section{Materials and methods}

\subsection{Plants and sampling}

Twelve families of highbush blueberry from a $3 \times 4$ factorial crossing plan were established at the Wilhelm Dierking Beerenobst in Gilten, Germany $\left(52^{\circ} 47^{\prime} \mathrm{N} 9^{\circ} 7^{\prime} \mathrm{E}\right)$ in family blocks of ten seedlings each (single block of 10 seedlings per each family, 120 seedlings in total). The mating design included three female parents ('Duke', 'Reka' and 'Sharpblue') crossed with four male parents ('Brigitta Blue', 'Elizabeth', 'Hortblue Petite' and 'Star'). Except for 'Hortblue Petite', the rest of the parents used in this mating design are cultivars widely cultivated around the world for their yields, fruit quality and storage and seasonality in fruit harvest. Altogether the cultivation of the seven parents offers and extended berry harvest season at the Wilhelm Dierking Beerenobst from early ('Star', 'Duke' and 'Reka'), to mid season ('Brigitta Blue', 'Sharpblue' and 'Hortblue Petite') to late season ('Elizabeth'). 'Hortblue Petite' is an ornamental variety released by PFR which has shown consistently high phytochemical compositions according to previous evaluations [19].

Parental plants were growing in an adjacent field to the seedling blocks, in single plot of three plants.

Fully ripe fruit were collected from each seedling and parent during summer 2009, when seedlings were 4 years old and when $40-70 \%$ of the fruit on the plant were ripe (single harvest of 100-200 g). Fruit traits were recorded within 2 hours from the harvest.

Fruit weight (FW) was recorded on a 20 fruit sample per plant. On the same fruit sample, fruit colour (C), pedicel scar size (PSS) and firmness (F) were scored using a 1-9 rating scale with 1 being very poor (dark colour, large scar, soft) and 9 being exceptional (light blue colour, small scar size and firm). Scores of 6 or above indicated acceptable fruit quality, and similar scales were in use by other researchers [20-22].

\subsection{Phytochemical assessments}

A further 50 to 100 -g fruit sample per plant was collected and stored at $-20^{\circ} \mathrm{C}$ before shipping at Università Politecnica delle Marche (Italy) for the analyses of their phytochemical compounds content. A $10 \mathrm{~g}$ sub-sample was taken and placed in a tube for alcohol extraction by the method described in Scalzo et al. [23]. The phytochemical composition was assessed on the resulting fruit extracts by measuring the total anthocyanin content (ACY), the total phenolic content (TPH) and the total antioxidant activity (TAA). 
ACY was measured by the $\mathrm{pH}$ differential shift method [24]. The results were expressed as mg cyanidin-3-glucoside equivalent/100 g FW.

TPH was evaluated by the Folin-Ciocalteu's reagent method [25] using gallic acid as the standard for the calibration curve, and results were calculated and expressed as mg gallic acid equivalent/g FW.

The TAA was assessed by the ferric reducing antioxidant power (FRAP) method based on that reported by [26] and modified by [27] and measured as $\mu \mathrm{mol}$ Trolox equivalent/g FW.

\subsection{Statistical methodology}

Data were analysed using restricted maximum likelihood procedures. Univariate mixed models were fitted, with the parental cultivars as fixed effects and parents (i.e., female and male half-sib values) plus full-sib family values as random effects. Parental (sib) effects were modelled as $N\left(0, A \sigma_{A}{ }^{2}\right)$, where $A$ is the numerator relationship matrix and the additive genetic variance, $\sigma_{A}{ }^{2}$, was estimated for female and male parents separately. Best linear unbiased predictors (BLUP) were used to estimate the empirical breeding values (eBV) of the parents, and these were compared with the values obtained for the parents harvested from an adjoining area. All statistical analyses and graphics were made using R 2.10.1 [28] and the mixed modelling procedures using the ASReml package [29].

\section{Results and discussion}

None of the seven parents we used in our mating design had all the desirable fruit traits.

In our factorial mating design, parents were mated in a way to avoid degrees of inbreeding per each cross combination. The calculation of coancestries is shown in Table 1 and in our mating scheme they were low overall ( 0.18 being the highest between the female parent 'Reka' and the male parent 'Star'). A higher degree of inbreeding would have been present if the female parents 'Reka' and 'Duke' had been reciprocally crossed (coancestry value 0.21 ) and if every parent was crossed with itself (coancestries ranged between 0.50 and 0.60 , Table 1 ).

The population size was smaller than ideal, with single replication and single year evaluation to make strong statistical evaluation and conclusions. Thus we report our observations on parents as estimate of their empirical breeding values (eBV) (Table 2a), factors affecting variance as percentage of the single factor compared to the total variation (Table 2b), mid parent values and families as averages (Table 3 ).

The three female parents had similar eBVs for FW, TAA and TPH (Table 2a) and overall the female factor led to $0 \%$ of the total variance for these traits (Table $2 \mathrm{~b}$ ).

There were differences in eBVs amongst the three female parents for C, PSS, F and ACY however the female parent accounted only for the $2 \%$ of the total variation for PSS (Table $2 b$ ).

Table 1

Coancestry matrix of the parental blueberry genotypes. Coancestries of an individual with itself (diagonal values) $>0.5$ indicates some degree of inbreeding and is shown in bold

\begin{tabular}{|c|c|c|c|c|c|c|c|c|}
\hline & & \multicolumn{3}{|c|}{ Males } & \multirow[b]{2}{*}{ 'Star' } & \multicolumn{3}{|c|}{ Females } \\
\hline & & 'Brigitta Blue' & 'Elizabeth' & 'Hortblue Petite' & & 'Duke' & 'Reka' & 'Sharp-Blue' \\
\hline \multirow[t]{4}{*}{ Males } & 'Brigitta Blue' & 0.50 & 0.06 & 0.13 & 0.07 & 0.14 & 0.10 & 0.06 \\
\hline & 'Elizabeth' & 0.06 & 0.53 & 0.00 & 0.06 & 0.11 & 0.11 & 0.03 \\
\hline & 'Hortblue Petite' & 0.13 & 0.00 & 0.50 & 0.00 & 0.00 & 0.00 & 0.03 \\
\hline & 'Star' & 0.07 & 0.06 & 0.00 & 0.57 & 0.15 & 0.18 & 0.06 \\
\hline \multirow[t]{3}{*}{ Females } & 'Duke' & 0.14 & 0.11 & 0.00 & 0.15 & 0.60 & 0.21 & 0.06 \\
\hline & 'Reka' & 0.10 & 0.11 & 0.00 & 0.18 & 0.21 & 0.59 & 0.09 \\
\hline & 'Sharpblue' & 0.06 & 0.03 & 0.03 & 0.06 & 0.06 & 0.09 & 0.53 \\
\hline
\end{tabular}


Table 2

(a) Blueberry parental empirical breeding values (eBV) and their standard errors (SE) for each trait; (b) the major source of variation for female and male parents, family and the residual is expressed as percentage (\%) for each trait

\begin{tabular}{|c|c|c|c|c|c|c|c|c|c|c|c|c|c|c|}
\hline & \multicolumn{2}{|c|}{ FW } & \multicolumn{2}{|c|}{$\mathrm{C}$} & \multicolumn{2}{|c|}{ PSS } & \multicolumn{2}{|c|}{$\mathrm{F}$} & \multicolumn{2}{|c|}{ TAA } & \multicolumn{2}{|c|}{$\mathrm{ACY}$} & \multicolumn{2}{|c|}{$\mathrm{TPH}$} \\
\hline & $\mathrm{eBV}$ & SE & eBV & SE & eBV & SE & eBV & SE & eBV & SE & eBV & SE & eBV & SE \\
\hline \multicolumn{15}{|l|}{ (a) eBV } \\
\hline 'Duke'우 & 1.8 & 0.17 & 6.8 & 0.61 & 5.8 & 0.67 & 6.8 & 0.69 & 17.6 & 1.45 & 145 & 15.3 & 3.9 & 0.27 \\
\hline 'Reka'우 & 1.8 & 0.17 & 6.0 & 0.61 & 6.0 & 0.67 & 5.9 & 0.69 & 17.6 & 1.45 & 136 & 15.4 & 3.9 & 0.27 \\
\hline 'Sharpblue'o & 1.8 & 0.17 & 6.2 & 0.61 & 6.1 & 0.66 & 5.7 & 0.68 & 17.6 & 1.45 & 120 & 15.2 & 3.9 & 0.27 \\
\hline 'Brigitta Blue' ${ }^{\top}$ & 1.8 & 0.27 & 5.8 & 0.59 & 6.1 & 0.70 & 6.5 & 0.71 & 17.4 & 2.18 & 129 & 18.1 & 3.8 & 0.43 \\
\hline 'Elizabeth' ఠ' & 2.2 & 0.27 & 6.2 & 0.59 & 5.8 & 0.71 & 6.1 & 0.71 & 16.7 & 2.18 & 113 & 18.1 & 3.8 & 0.43 \\
\hline 'Hortblue Petite' o' & 1.4 & 0.27 & 6.5 & 0.58 & 5.7 & 0.70 & 5.0 & 0.70 & 21.0 & 2.17 & 164 & 18.1 & 4.6 & 0.42 \\
\hline 'Star' o' & 1.9 & 0.27 & 6.9 & 0.59 & 6.4 & 0.71 & 7.1 & 0.71 & 14.1 & 2.18 & 111 & 18.2 & 3.3 & 0.43 \\
\hline \multicolumn{15}{|l|}{ (b) $\%$ variation } \\
\hline Female & $0 \%$ & & $15 \%$ & & $2 \%$ & & $19 \%$ & & $0 \%$ & & $12 \%$ & & $0 \%$ & \\
\hline Male & $44 \%$ & & $17 \%$ & & $7 \%$ & & $35 \%$ & & $43 \%$ & & $41 \%$ & & $38 \%$ & \\
\hline Family & $4 \%$ & & $5 \%$ & & $3 \%$ & & $4 \%$ & & $0 \%$ & & $0 \%$ & & $13 \%$ & \\
\hline Residual & $52 \%$ & & $63 \%$ & & $88 \%$ & & $42 \%$ & & $57 \%$ & & $47 \%$ & & $49 \%$ & \\
\hline
\end{tabular}

$q=$ female parent; $\sigma^{\top}=$ male parent. $\mathrm{FW}=$ fruit weight $(\mathrm{g}) ; \mathrm{C}=$ colour; $\mathrm{PSS}=$ pedicel scar size; $\mathrm{F}=$ firmness; TAA = $\mu$ mol Trolox equivalent $/ \mathrm{g} F W$; $\mathrm{ACY}=$ total anthocyanin content as mg cyanidin-3-glucoside equivalents $/ 100 \mathrm{~g} \mathrm{FW}$;PH $=$ total phenolic content as mg gallic acid equivalent/g FW. Rating scales for C, PSS and F: $1=$ absent (poorest) $9=$ extreme (best) $6=$ acceptable.

In contrast, there were large differences in eBVs amongst the four male parents for all the traits although the variance attributable to male parent compared with the total variance was low for $\mathrm{C}$ and PSS, $17 \%$ and $7 \%$ respectively (Table 2b).

The variance attributable to the family was overall low for all the traits with TPH being the highest (13\%) while the variance relative to the residual was high in particular for PSS (88\%).

Variation amongst families was found for all fruit traits, and mid parent values, family averages and min and max value within each family are reported on Table 3.

For those traits where female parents had similar eBVs (FW, TAA and TPH) the mid parent value was influenced by the male parent eBV. 'Elizabeth' had the highest eBV for FW (Table 2a). The mid parent value and the family averages when this cultivar was used as the pollen donor were also high for FW (Table 3). In contrast, 'Hortblue Petite' was the male parent with the lowest eBV for FW (Table 2a) and the mid parent value and the family averages when this cultivar was used as pollen donor were also low (Table 3 ).

Fruit weight is generally considered to be a highly heritable trait across most fruit crops, which suggested that by crossing highbush blueberry parents with large fruit such as 'Elizabeth', the breeders could gain significant progress in selecting for this individual trait.

The eBVs for $\mathrm{C}$ were at least acceptable (6 or more) for all the parents except 'Brigitta Blue' (5.8). Mid parent values and family averages from 'Brigitta Blue' crosses were variable and the family derived from the 'Brigitta Blue' $\times$ 'Reka' cross had the lowest mean values (Table 3).

The eBVs for PSS were variable among parents and for the parents 'Duke', 'Elizabeth' and 'Hortblue Petite', the estimate values were not acceptable (below 6). Mid parent values for those families involving the three parents were low compared with those from other cross combinations. The family averages for PSS were variable between crosses and did not reflect the mid parent value.

eBVs for F were variable among parents, ranging between 5 and 7.1 ('Hortblue Petite' and 'Star' respectively). Mid parent values for F in those families where 'Hortblue Petite' was used as the pollen donor were low compared those for other male parents, and family averages were also low, as found for FW. Mid parent values in those families where 'Star' was used as the male parent were high, and similarly family averages were also high. 


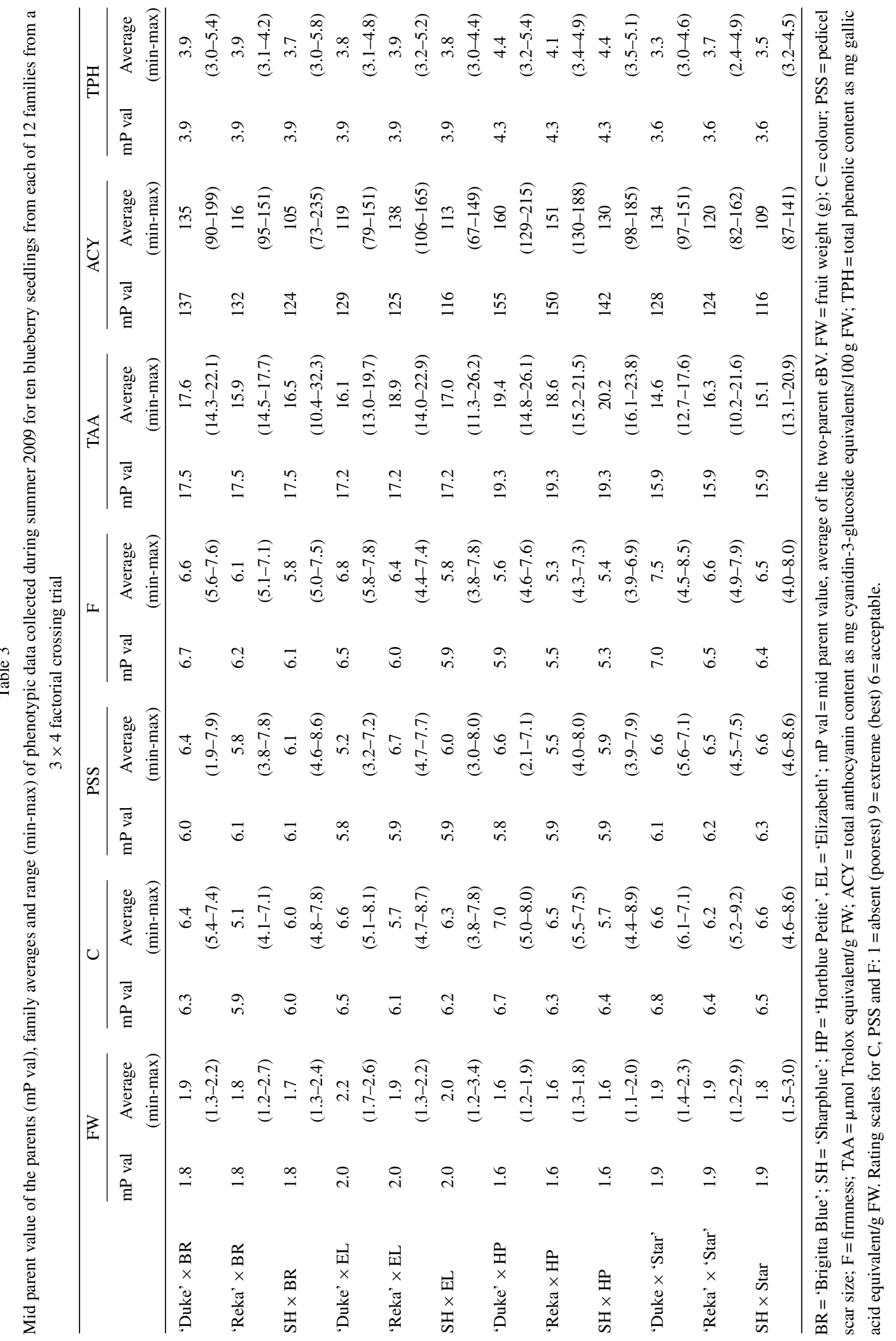


Table 4

Genetic correlations between blueberry fruit traits and phytochemicals. Significant correlations are highlighted in bold

\begin{tabular}{lcccrrr}
\hline & C & PSS & F & TAA & ACY & TPH \\
\hline FW & \multirow{2}{*}{0.03} & 0.06 & 0.29 & $\mathbf{- 0 . 4 8}$ & $-\mathbf{0 . 4 8}$ & $-\mathbf{0 . 5 0}$ \\
C & & 0.10 & 0.15 & 0.09 & 0.08 & 0.09 \\
PSS & & & 0.14 & -0.07 & -0.16 & -0.10 \\
F & & & & -0.39 & -0.23 & -0.33 \\
TAA & & & & & $\mathbf{0 . 7 5}$ & $\mathbf{0 . 8 8}$ \\
ACY & & & & & & $\mathbf{0 . 7 6}$ \\
\hline
\end{tabular}

$\mathrm{FW}=$ fruit weight $\mathrm{C}=$ colour; $\mathrm{PSS}=$ pedicel scar size; $\mathrm{F}$ = firmness; TAA = ferric reducing antioxidant power; $\mathrm{ACY}=$ total anthocyanin content $\mathrm{TPH}=$ total phenolic content.

Parental eBVs for TAA, ACY and TPH were high for 'Hortblue Petite' and low for 'Star'. Mid parent values and family averages in families where these two cultivars were used as the male parent reflected the eBVs.

The cross combinations with 'Hortblue Petite' as the pollen donor were the ones with the highest mid parent values for the phytochemical traits (Table 3 ) and high family averages could confirm that in highbush blueberries, parental performance can be used as a good indicator of progeny performance, as already discussed by different authors [21, 30-33].

Previous reports suggest that the genetic variation and the inheritance of fruit traits and phytochemicals of fruit vary amongst the different cross combinations [22, 30, 33].

Genetic correlations among all the variables on a genotype mean basis for the 120 offspring are shown in Table 4 . Low correlations were found between fruit traits $(0.03$ between FW and $\mathrm{C}$ being the lowest, and 0.29 between FW and $\mathrm{F}$ being the highest). High and significant correlations were found between all phytochemicals ( 0.75 between TAA and ACY being the lowest, and 0.88 between TAA and TPH being the highest), suggesting that either method could be used to assess the presence of those compounds in fruit. The strong and positive correlations between the total anthocyanins, total phenolics and antioxidant activity are also reported by other authors [34-38].

A negative and significant correlation was found between FW and ACY (Table 4), which could make pursuing a selection for fruit suitable for hand harvesting based solely on fruit size undesirable, because it could have a negative effect on fruit ACY. Similarly, negative and significant correlations were found between FW and TAA $(-0.48)$, and between FW and TPH $(-0.50)$. In the blueberry samples analysed in this work, anthocyanins were mostly concentrated in the berry skin and evidences of V. corymbosum berry skin rich in anthocyanins was found by Lee [39]. Therefore when comparing the same quantities of fruit from samples which have different sized fruit, the small sized fruit will offer a relatively higher skin area and consequently more anthocyanins.

ACY with TAA and TPH also had negative correlations with PSS and F but not significant, suggesting that the response to selection could be slow for these traits and phytochemicals if selected together (Table 4).

Anthocyanins are also the compounds responsible for the blueberry fruit colour. In our assessment, we evaluated the colour when the berry was harvested and intact, with its bloom wax covering the fruit. The waxy coat on the fruit contributed to the perceived fruit colour and according to our results was independent from ACY (Table 4). Low genetic correlation was also found between $\mathrm{C}$ and the other phytochemicals.

In previous reports on highbush blueberries, crosses with one or both parents having light blue fruit produced many progeny with light blue fruit [21, 40, 41]. Edwards et al. [21] reported a moderate narrow-sense heritability estimate of 0.58 for colour, although year-to-year environmental variation resulted in inconsistent scoring. They concluded that parents chosen for their bright fruit colour should transmit the desirable colour characters to their progenies.

Even though little genetic variation was observed for PSS in several studies, including ours [41-43], certain parents have been noted for producing progenies with superior scars [21, 40, 44, 45]. Edwards et al. [21] reported low heritability for scar (0.29); however, they concluded that genetic gain should also be obtained for this character, although the rate of gain would not be expected to be as rapid as for traits possessing high heritabilities, such as fruit size. 
In previous reports, highbush blueberries were found to be variable in fruit firmness [21, 22, 41, 46]. Draper [46] rated $84 \%$ of the seedlings derived from V. corymbosum to have acceptable firmness, while Johnston [41] found that the proportion of seedlings with acceptable firmness from crosses among acceptable highbush parents ranged from $16 \%$ to $63 \%$. While these historical studies are valuable, one of the challenges current breeders face is the fact that expectations of what is acceptable by the industry for fruit firmness are much higher now than they were in the past due to global distribution of fresh fruit.

Connor et al. [30] reported a moderate heritability for total anthocyanin content of 0.56 , which indicates that selecting parents on the basis of their observed anthocyanin content should be moderately successful. Experimental design to account for sources of variability in anthocyanins, such as cultural conditions [47], year [34], fruit maturity [48], and storage conditions [49, 50], should increase the heritability.

\section{Conclusions}

Although the population size was smaller than ideal and single replication and single year evaluation made the statistical approach difficult, we have improved our basic understanding of the feasibility of breeding for the traits of interest from the variation present in our population and from the parent's performances in passing on their traits to their progenies.

We have gained knowledge of the performances of 'Hortblue Petite' as a potentially excellent parent for fruit phytochemical triats. The cross combinations with 'Hortblue Petite' as the pollen donor were the ones with the highest mid-parent values and high family averages for all the phytochemical traits. 'Hortblue Petite' also seems to pass on small fruit size to its progeny and a simultaneous strong selection pressure for fruit size may be necessary to identify the transgressive segregants that have high phytochemical levels and large fruit size.

High and significant correlations were found between phytochemicals which suggests that either method could be used to assess the presence of those compounds in fruit and measuring more than one of them will not be necessary in future studies to identify the seedlings that would have the highest levels of these compounds.

Although scoring system to assess fruit traits is widely used by different authors, we found scoring PSS unreliable in our study and we will explore the use of an alternative method to measure objectively the pedicel scar size of blueberry.

\section{Acknowledgments}

This project was funded by Wilhelm Dierking Beerenobst and Plant \& Food Research. The analyses of the phytochemical composition of fruit were performed at the Università Politecnica delle Marche, Italy. We would like to acknowledge the help of Valentina Sguigna in completing the phytochemical analyses of fruit.

\section{References}

[1] Crawford K, Mellentin J. Successful superfruit strategy: How to build a superfruit business. Cambridge, UK: Woodhead Publishing; 2008.

[2] Giampieri F, Tulipani S, Alvarez-Suarez JM, Quiles JL, Mezzetti B, Battino M. The strawberry: Composition, nutritional quality, and impact on human health. Nutrition 2012;28:9-19.

[3] Stevenson D, Hurst R. Polyphenolic phytochemicals - just antioxidants or much more? Cell Mol Life Sci 2007;64:2900.

[4] Stevenson D, Lowe T. Plant-derived compounds as antioxidants for health - are they all really antioxidants? Func Plant Sci Biotechnol 2009;3(S1):1.

[5] Stevenson D. New antioxidant mechanisms and functional foods. Part 2. Agro Food Industry hi-tech 2012;23:34.

[6] Stevenson D. New antioxidant mechanisms and functional foods. Part 1. Agro Food Industry hi-tech 2012;23:32.

[7] Del Rio D, Borges G, Crozier A. Berry flavonoids and phenolics: Bioavailability and evidence of protective effects. British Journal of Nutrition 2010;104:67-90.

[8] Ghosh D. Anthocyanins and anthocyanin-rich extracts in biology and medicine: Biochemical, cellular, and medicinal properties. Current Topics in Nutraceutical Research 2005;3:113-24. 
[9] Ghosh D, McGhie TK, Zhang J, Adaim A, Skinner M. Effects of anthocyanins and other phenolics of boysenberry and blackcurrant as ihibitor of oxidative stress and damage to cellular DNA in SH-SY5Y and HL-60 cells. J Sci Food Agric 2006;86:678-86.

[10] He J, Giusti M. Natural Colorants with Health-Promoting Properties. Annual Review of Food Science and Technology $2010 ; 1: 163$.

[11] Kaume L, Howard L, Devareddy L. The blackberry fruit, its composition and chemistry, metabolism and bioavailability, and health benefits. J Agric Food Chem 2011;60:5716-27.

[12] Lee J, et al. Purified high-dose anthocyanoside oligomer administration improves nocturnal vision and clinical symptoms in myopia subjects Br J Nutr 2005;93(6):895-9.

[13] Lyall KA, et al. Short-term blackcurrant extract consumption modulates exercise-induced oxidative stress and lipopolysaccharide-stimulated inflammatory responses. American Journal of Physiology-Regulatory Integrative and Comparative Physiology 2009;297(1):70-81.

[14] Matsumoto H, Nakamura Y, Tachibanaki S, Kawamura S, Hirayama M, Stimulatory effect of cyaniding 3-glycosides on the regeneration of rhodopsin. J Agric Food Chem 2003;51:3560-3.

[15] Matsumoto $\mathrm{H}$, et al. Effects of blackcurrant anthocyanin intake on peripheral muscle circulation during typing work in humans. Eur J Appl Physiol 2005;94(1-2):36-45.

[16] Shin WH, Park SJ, Kim EJ, Protective effect of anthocyanins in middle cerebral artery occlusion and reperfusion model of cerebral ischemia in rats. Life Sci 2006;79:130-7.

[17] Scalzo J, Currie A, Stephens J, McGhie T, Alspach P, The anthocyanin composition of different Vaccinium, Ribes and Rubus genotypes. BioFactors 2009; 34(1):13-21.

[18] Wang SY, Chen H, Camp MJ, Ehlenfeldt MK. Flavonoid consituents and their contribution to antioxidant activity in cultivars and hybrids of rabbiteye blueberry (Vaccinium ashei Reade). Food Chemistry 2012;132:855-64.

[19] Scalzo J, Miller S, Edwards C, Alspach P. 'Hortblue Onyx' and 'Hortblue Petite': Two new ornamental blueberries from New Zealand. Acta Horticulturae 2009;810:153-6.

[20] Ballington JR, Ballinger WE, Swallow WH, Galletta GJ, Kushman LJ. Fruit-Quality Characterization of 11 Vaccinium Species. Journal of the American Society for Horticultural Science 1984;109(5):684-9.

[21] Edwards TW, Jr. Sherman WB and Sharpe RH, Evaluation and inheritance of fruit color, size, scar, firmness and plant vigor in blueberry. HortScience 1974; 9(1):20-22

[22] Finn CE, Luby JJ. Inheritance of fruit quality traits in blueberry. Journal of the American Society for Horticultural Science 1992;117(4):61721.

[23] Scalzo J, Miller S, Edwards C, Meekings J, Alspach P. Variation in phytochemical composition and fruit traits of blueberry cultivars and advanced breeding selections in New Zealand. Acta Horticulturae 2009;810:823-30.

[24] Giusti MM, Wrolstad RE, Characterization and measurement of anthocyanins by UV-visible spectroscopy. In. Current Protocols Food Analytical Chemistry. John Wiley \& Sons, Inc; 2001.

[25] Slinkard K, Singleton VL. Total phenol analysis: Automation and comparison with manual methods. Am J Enol Vitic 1997;28:49-55.

[26] Deighton N, Brennan R, Finn C, Davies HV, Antioxidant properties of domesticated and wild Rubus species. J Sci Food Agric 2000;80:130713.

[27] Connor AM, Stephens MJ, Hall HK, Alspach PA, Variation and heritabilities of antioxidant activity and total phenolic content estimated from a red raspberry factorial experiment. J Amer Soc Hort Sci 2005;130(3):403-11.

[28] Team. RDC, R: A language and environment for statistical computing. R Foundation for Statistical Computing, Vienna, Austria. ISBN 3-900051-07-0, URL http://www.R-project.org/. 2009, Available from: http://www.R-project.org.

[29] Butler D. asreml: Asreml() fits the linear mixed model. R package version 3.00. 2009

[30] Connor AM, Luby JJ, Tong CBS. Variation and heritability estimates for antioxidant activity, total phenolic content, and anthocyanin content in blueberry progenies. J Am Soc Hort Sci 2002;127(1):82-8.

[31] Coville FV. Improving the wild blueberry US Dept Agr Yrbk Agr 1937:559-74.

[32] Diamanti J, et al. Increasing Strawberry Fruit Sensorial and Nutritional Quality Using Wild and Cultivated Germplasm. PLoS ONE 2012;7(10):e46470. doi:46410.41371/journal.pone.0046470

[33] Diamanti J, Capocasa F, Battino M, Mezzetti B. Evaluation of F. x ananassa intra-specific and inter-specific back-crosses to generate new genetic material with increased fruit nutritional quality. Journal of Berry Research 2010;1:103-4.

[34] Connor AM, Luby JJ, Tong CBS, Finn CE, Hancock JF. Genotypic and environmental variation in antioxidant activity, total phenolic content, and anthocyanin content among blueberry cultivars. J Am Soc Hort Sci 2002;127(1):89-7.

[35] Ehlenfeldt MK, Prior RL. Oxygen radical absorbance capacity (ORAC) and phenolic and anthocyanin concentrations in fruit and leaf tissues of highbush blueberry. Journal of Agricultural and Food Chemistry 2001;49(5):2222-7.

[36] Moyer RA, Hummer KE, Finn CE, Frei B, Wrolstad RE. Anthocyanins, phenolics, and antioxidant capacity in diverse small fruits: Vaccinium, Rubus, and Ribes. Journal of Agricultural and Food Chemistry 2002;50(3):519-25.

[37] Prior RL, et al. Antioxidant Capacity as Influenced by Total Phenolic and Anthocyanin Content, Maturity and variety of Vaccinium Species. J Agr Food Chem 1998;46:2686-93.

[38] Sellapan S, Akoh CC, Krewer G. Phenolic compounds and antioxidant capacity of Georgia-grown blueberries and blackberries. J Agr Food Chem 2002;50:2432-8. 
[39] Lee J, Wrolstad RE. Extraction of Anthocyanins and Polyphenolics from Blueberry Processing Waste. J Food Science 2004;69:C564-C73.

[40] Darrow GM, Clark JH, Morrow EB. The inheritance of certain characters in the cultivated blueberry. Proc Amer Soc Hort Sci 1939;37:611-6.

[41] Johnston S. Observations on the inheritance of horticulturally important characteristics in the highbush blueberry. Proc AmerSoc Hort Sci 1942;40:352-6

[42] Ballington JR, Isenberg YM, Draper AD. Flowering and fruiting characteristics of Vaccinium ashei and Vaccinium ashei-Vaccinium constablaei derivative blueberry progenies. Journal of the American Society for Horticultural Science 1986;111(6):950-5.

[43] Darrow GM, Morrow EB, Scott DH. An evaluation of interspecific blueberry crosses. Proc Amer Soc Hort Sci 1952;59:277-82.

[44] Johnston S. Blueberry breeding in Michigan. Fruit Var Hort Dig 1956:11-20.

[45] Luby JJ, Ballington JR, Draper AD, Pliszka K, Austin ME. Blueberry and Cranberry (Vaccinium). In: Ballington JNMaJR, editor. Genetic Resources of Temperate Fruit and Nut CropsIntl. Soc Hort Sci, Wageningen, The Netherlands; 1990. pp. 391-456.

[46] Draper AD, Galletta GJ, Ballington JR. Breeding methods for improving southern tetraploid blueberries. Journal of the American Society for Horticultural Science 1982;107(1):106-9.

[47] Wang SY, Chen C-T, Sciarappa W, Wang CY, Camp MJ. Fruit Quality, Antioxidant Capacity, and Flavonoid Content of Organically and Conventionally Grown Blueberries. J Agr Food Chem 2008;56:5788-94.

[48] Castrejon ADR, Eichholz I, Rohn S, Kroh LW, Huyskens-Keil S. Phenolic profile and antioxidant activity of higbush blueberry (Vaccinium corymbosum L.) during fruit maturation and ripening. Food Chemistry 2008;109:564-72.

[49] Connor AM, Luby JJ, Hancock JF, Berkheimer S, Hanson EJ. Changes in fruit antioxidant activity among blueberry cultivars during cold-temperature storage. J Agr Food Chem 2002;50:893-8.

[50] Kalt W, Forney CF, Martin A, Prior RL. Antioxidant capacity, Vitamin C, phenolics, and anthocyanins after fresh storage of small fruits. J Agr Food Chem 1999;47:4638-44. 